Appetite, 1992, 18, 207-221

\title{
Food Preferences in Human Obesity: Carbohydrates Versus Fats
}

\author{
ADAM DREWNOWSKI, CANDACE KURTH, JEANNE HOLDEN-WILTSE \\ and JENNIFER SAARI \\ Human Nutrition Program, School of Public Health, The University of Michigan
}

\begin{abstract}
A large clinical sample of obese men and women were asked for a self-generated list of ten favorite foods. The lists were characterized by frequent instances of foods that are major nutrient sources of fat in the American diet. While obese men listed mainly protein/fat sources (meat dishes) among their favorite foods, obese women tended to list predominantly carbohydrate/fat sources (doughnuts, cookies, cake) and foods that were sweet. There was no evidence that selective preferences for a single macronutrient, carbohydrate, were a standard feature of human obesity. Rather, preferences for major nutrient sources of fat as opposed to carbohydrate may be a primary characteristic of human obesity syndromes.
\end{abstract}

\section{INTRODUCTION}

Excessive consumption of a single macronutrient, carbohydrate, is said to be a major factor in the development of human obesity (Wurtman, 1984). Obese persons are reputed to show a specific appetite for carbohydrate-rich foods, selecting carbohydrates as meals or snacks even though other foods may be available (Lieberman et al., 1986; Wurtman et al., 1981, 1985). Cravings for carbohydrates have been reported to affect a majority of obese patients (Heraief et al., 1985; Lieberman et al., 1986), and excessive carbohydrate intake is viewed as an important contributor to the obese state (Wurtman \& Wurtman, 1984).

In contrast, other studies have suggested that dietary fat plays a major role in human obesity. Dietary intake studies have shown that obese women consumed more fat calories than did lean women and had a lower dietary carbohydrate-to-fat ratio (Romieu et al., 1988). In taste preference studies with sugar/fat mixtures, massively obese women preferred sensory stimuli that were relatively low in sugar but were rich in fat (Drewnowski et al., 1985). More recently, high levels of body fat have been correlated with the amount of fat in the diet (Dreon et al., 1988) and with sensory preferences for high levels of fat in foods (Mela \& Sacchetti, 1991).

A systematic study of food preferences in an obese population would help determine whether obese individuals prefer carbohydrates as opposed to fat-rich foods. However, apart from some clinical observations and anecdotal reports, little is known about food preferences in human obesity (Drewnowski, 1990). The main research focus has been on sensory preferences for sweet taste and the potential 
overconsumption of sweet desserts (Meiselman, 1977; Gates et al., 1975). Such concepts as "sweet tooth" (Anonymous, 1990) and "carbohydrate craving" (Wurtman, 1984) have contributed to the popular notion that starches and sugars are the characteristic food choices of obese individuals.

Measures of food preference are generally viewed as sensitive predictors of food consumption (Blundell \& Hill, 1988). For example, food preference instruments, used in large-scale studies of U.S. Army personnel, successfully established relative preferences for all 346 foods served on the army menus (Meiselman, 1977; Meiselman \& Waterman, 1978). In most studies the subjects were asked to rate their preference for a number of foods using visual analog or category scales (Logue \& Smith, 1986; Meiselman, 1977; Tomelleri \& Grunewald, 1987). Alternatively, the subjects checked the names of those foods they most felt like consuming at the time (Blundell \& Hill, 1988; Hill \& Blundel, 1982/83).

Food preference instruments can be used to assess relative preferences for a given food, or even food category. For example, in a study by Tomelleri \& Grunewald (1987), preferences for chocolate cake, chocolate candy bar, chocolate ice cream, chocolate chip cookies, and chococlate milk were used to assess the subjects' cravings for chocolate. However, in other studies, preferences for individual foods have been taken as an index of underlying preferences for selected macronutrients: carbohydrate, protein, or fat (Blundell \& Hill, 1988; Hill \& Blundell, 1982/83). Thus, a short checklist of 20 food names divided by the experimenters into high-protein and high-carbohydrate items (Blundell \& Rogers, 1980) was used to detect selective lowering of preferences for a single macronutrient, carbohydrate after fenfluramine treatment. A longer checklist of 32 food names divided into high-carbohydrate, high-protein, and high-fat foods was subsequently used to assess changing preferences for these macronutrients following a lunch meal (Hill \& Blundell, 1982/83). Elsewhere, checklists of low-fat vs. high-fat foods were taken to indicate preferences for dietary fats among obese as opposed to lean women (Pangborn et al., 1985).

There are two major problems with using food preferences as indicators of underlying macronutrient preferences. The first is that people generally tend to think in terms of foods and not macronutrients. Many foods provide carbohydrate, protein, or fat in different amounts, and the perception of what constitutes a highcarbohydrate or a high-fat food is a value judgment that may involve both psychology and nutrition. Inevitably, misclassifications abound. The very term "carbohydrate craving" is a notorious example. This term, apparently coined by Paykel et al. (1973) was originally defined as "a ravenous appetite for a variety of sweet substances including chocolates, cake, pastry and ice cream". As a simple nutritional analysis reveals, such foods are not only sweet but they often derive the bulk of their calories from fat (Drewnowski, 1988). In other studies, Snickers bars and a vanilla ice cream sundae with whipped cream have been described as carbohydrate-rich foods (Chiodo \& Latimer, 1986; Wurtman et al., 1985). Again, the chief source of carbohydrate in chocolate and ice cream is sugar, and the principal source of calories is not carbohydrate but fat (Drewnowski, 1988). However, since sugar in sweet desserts tends to mask the perception of fat, especially in solid foods (Drewnowski, 1983; Drewnowski \& Schwartz, 1990), sweetness is the more salient sensory attribute. The ill-informed consumer may well believe that ice cream is a carbohydrate-rich food. For example, an obese woman who reported cravings for chocolate bars and ice cream described herself as being addicted to sugar, i.e. a selfidentified "carbohydrate craver" (Anonymous, 1990). 
The second problem with using food checklists to assess nutrient preferences is that checklist items are usually chosen on the basis of their macronutrient content (Hill \& Blundell, 1982/83). Now foods that are high in a given nutrient are not necessarily important sources of that nutrient in the population diet. For example, although avocados are rich in fat, their contribution to the total population fat intake in the U.S.A. is virtually zero (Block et al., 1985). Consequently, elevated preferences for avocados are not a meaningful index of the tendency by the American population to consume a high-fat diet. In contrast, foods that are often overlooked as important sources of a given nutrient may be quantitatively important to the population intake. For example, the category of white bread, rolls and crackers, seldom if ever found on the list of high-fat foods, in the sixth largest contributor of total fat calories to the American diet (Block et al., 1985).

The factor that is often overlooked in the construction of food checklists is the habitual frequency of food consumption by the population under study. Some foods, though rich in carbohydrate or fat are not important dietary sources of those nutrients on a population-wide basis, since they are eaten rarely or in small quantities and contribute only a minimal amount of the nutrient to the population diet. For example, preferences for hamburgers and preferences for avocados as sources of dietary fat should not be used as equivalent indices of fat consumption, since hamburgers, cheeseburgers and meatloaf contribute some $7 \%$ of fat calories to the U.S. diet, while avocados contribute almost none. What distinguishes the two foods is their relative frequency of consumption. As NHANFS II survey data indicate, 2,618 people per 10,000 population were consuming hamburgers on any given day, while only 109 per 10,000 were likely to be eating an avodaco (Block et al., 1985).

If food preference checklists are to predict the consumption of a given macronutrient within a population, they should be based on foods that are major sources of that nutrient in the population diet. Preferences for frequently eaten foods should be weighted more heavily than preferences for rarely eaten foods, since the latter are less likely to affect nutritional status of the population, or influence the development of obesity. Preferences for foods that are major sources of carbohydrate or fat calories are most likely to have the broadest impact on the nutritional status of the obese population.

The present study was accordingly based on preferences for foods that are major sources of carbohydrate, protein, and fat calories in the typical American diet (Block et al., 1985). These data were based on food intake patterns of 11,658 adult respondents in the NHANES II studies. There is at present no specific information as to whether the same or different foods contribute the maximum amount of carbohydrate or fat calories to the diet of the obese population. However, obesity in the U.S.A. is a widespread condition (Najjar \& Rowland, 1987). Up to $40 \%$ of American adults are reported to be obese, and the obese population is said to number tens of millions of people. It is therefore likely that the national trends in food consumption will be shared to a large extent by the obese population. Consequently, if human obesity is indeed characterized by "carbohydrate cravings" and excessive carbohydrate consumption (Wurtman \& Wurtman, 1984), then the obese state should be associated with heightened preferences for major sources of carbohydrate in the U.S. diet. Conversely, consistent selection of a fat-rich diet by obese people should be reflected in more widespread preferences for the chief nutrient sources of fat. 


\section{METHODS}

\section{Subjects}

The subjects were 93 obese men and 386 obese women outpatients at two hospital-based weight loss programs: Weight Control Unit, St Luke's-Roosevelt Hospital Center, Columbia University, New York $(n=238)$, and the Obesity Rehabilitation Clinic, University of Michigan Hospitals, Ann Arbor $(n=241)$. Data for patients in the Weight Control Unit were obtained through a review of patient questionnaires administered during the initial evaluation phase and prior to the commencement of weight-loss therapy. Restraint scores (Herman, 1975) were obtained for a majority of the patients. The patients were subsequently enrolled in a 10-12 week behaviorally oriented therapeutic weight loss program, which included diet, exercise, counseling and nutrition education components. Patients at the Obesity Rehabilitation Center were also tested at the time of initial evaluation. These patients were then put on a $600 \mathrm{kcal} /$ day diet for a period of 6 months, and took part in nutrition education and counseling sessions. As in most weight reduction programs, the majority of patients in both clinics were middle-aged females.

\section{PROCEDURES}

Each subject was asked to write down ten of his or her favorite foods, including those that contributed to their overeating. The food preference list was part of a larger questionnaire addressing the relationship between eating habits and overweight, which are subjects completed on entry into the program. Because some subjects listed fewer than ten foods, the number of favorite foods listed was 886 for men and 3,638 for women for a total of 4,524 food names.

In the first set of analyses, the 4,524 foods were assigned to 147 food categories, as derived by Block et al. (1985). Block et al. (1985) came up with a list of 147 food categories representing foods most frequently eaten by 11,658 adult respondents in the NHANES II survey, 1976-80, in descending order according to the number of persons consuming them. Since the NHANES II survey used as many as 2,244 different food codes, each of the 147 food categories represented several NHANES food codes. The foods had been grouped together becausc they wcre conccptually similar or because they had similar nutrient content per serving. Block et al. (1985) then calculated the percentage contribution of each food category to the carbohydrate, protein and fat content of the U.S. diet. That calculation was based on the food's nutrient content and its estimated frequency of consumption. Published lists of the top 50 sources of carbohydrate, protein and fat show that 50 food categories per nutrient accounted for over $90 \%$ of that nutrient's intake in the American diet (Block et al., 1985).

The first set of analyses was limited to the top 25 sources of carbohydrate, protein, and fat. The top 25 sources of carbohydrate accounted for a cumulative total of $76 \%$ of carbohydrate calories; top 25 sources of protein for $81 \%$ of protein calories; and 25 top sources of fat for $82 \%$ of fat calories. The fact that the mean number of unique foods consumed over a 3-day period is 25 
(Smiciklas-Wright et al., 1986) was an additional consideration. This number is largely independent of age and sex. Sixty-nine per cent of all 4,524 favorite foods listed by obese subjects were among the top 25 sources of carbohydrate, protein, or fat. Because many foods provided more than one macronutrient, the three lists contained 48 unique food categories.

Two scores were calculated for each of the 48 food categories. The subject percentage score was the percentage of subjects who named at least one food belonging to the category on their list of ten favorite items. Thus, a subject who listed doughnuts was counted as listing one item in the category "doughnuts, cookies, cake", and was included in the subject percentage score. However, the listing of additional items from the same category (e.g. cookies, or cake) by the same subject would not add to the subject percentage score. Comparisons of subject percentage scores between men and women were made using Chi-square tests.

The item frequency score was the average number of times that foods belonging to the same category were named by one subject. Thus, if the same subject listed, for example, chocolate chip cookies, cake, and doughnuts on his or her list, the item frequency score for the category of "doughnuts, cookies and cake" would be $3 \cdot 0$. Item frequency scores were calculated for the top 25 sources of carbohydrate, protein, and fat. Additional item frequency sources were calculated for those food categories that were among the top 25 sources of more than one macronutrient. For example, because doughnuts were among the top 25 sources of both carbohydrate and fat, the category of "doughnuts, cookies and cake" qualified as a carbohydrate/ fat source as well as a carbohydrate source. In contrast, chocolate candy was only a carbohydrate source under the present coding scheme, since chocolate candy was not among the top 25 fat sources in the U.S. diet (it was number 26). Differences in item frequency scores between men and women were analysed using $t$-tests, while differences between categories were analysed using paired $t$-tests.

The second set of analyses was based on the entire set of 4,524 food names, with no omissions. These foods were assigned to 11 mutually exclusive food groups based on the foods' nutrient contributions to the diet. Thus, white bread was assigned to the group of carbohydrate/fat sources due to its high ranking as a major contributor of both carbohydrate and fat to the diet. Subsequent analyses also employed percentage and frequency scores. Subject percentage score was the percentage of obese men and women who listed at least one instance of a food belonging to one of the 11 food groups among their favorites. Item frequency score was the average number of times that foods belonging to each of the 11 food groups appeared in a single list. Differences in item frequency scores between men and women were analysed using $t$-tests. Differences in subject percentage scores were analysed using chi-square tests.

\section{RESULTS}

\section{Subjects}

Subject characteristics are summarized in Table 1. The subjects' mean weights were $196.2 \mathrm{lbs}$ for women and $248.6 \mathrm{lbs}$ for men. The average age was $38.2 \mathrm{yrs}$ for women and $40.4 \mathrm{yrs}$ for men. As in most other studies, women outnumbered men 
TABLE 1

Summary of subject characteristics. Data are means and standard deviations (in parentheses)

\begin{tabular}{lrc}
\hline & Men $(n=93)$ & Women $(n=386)$ \\
\hline Age (yrs) & $40.4(11 \cdot 2)$ & $38.2(11 \cdot 7)$ \\
Height (in) & $69 \cdot 3(2 \cdot 7)$ & $64.8 \quad(2 \cdot 4)$ \\
Weight (lbs) & $248.6(57 \cdot 0)$ & $196 \cdot 2(44 \cdot 1)$ \\
BMI $\left(\mathrm{kg} / \mathrm{m}^{2}\right)$ & $36 \cdot 4 \quad(7 \cdot 9)$ & $32.9 \quad(6 \cdot 9)$ \\
Restraint score & $20.4 \quad(4 \cdot 2)$ & $21 \cdot 2 \quad(4 \cdot 8)$ \\
\hline
\end{tabular}

4 to 1 (Blackburn et al., 1989; Price et al., 1990). These subject characteristics are typical of patients in weight-loss clinics.

\section{Carbohydrate sources}

The top 25 sources of carbohydrate in the U.S. diet are listed in Table 2. These foods, which include numerous carbohydrate-rich snacks, contribute a cumulative total of $76 \cdot 3 \%$ of carbohydrate calories to the diet. According to Block et al. (1985), the category of white bread, rolls, and crackers is the largest single source of carbohydrate calories $(15.0 \%)$, being followed by non-diet soft drinks ( $8.5 \%)$, and doughnuts, cookies and cake $(7 \cdot 5 \%)$.

As shown in Table 2, 56.2\% of obese women named at least one item from the "doughnuts, cookies or cake" category among their favorite foods. Similarly, over half $(54.4 \%)$ of the women named among favorites at least one instance of white bread, rolls or crackers, while $51.3 \%$ listed ice cream as a favorite food. Named less frequently were pasta dishes (by $39.1 \%$ of the women), chocolate candy $(32.4 \%$ ), potatoes $(29 \cdot 5 \%)$ and salty snacks $(23 \cdot 8 \%)$.

Men were less likely to list carbohydrate sources among their favorite foods than were women. Fewer men than women listed instances of white bread, doughnuts, chocolate candy, salty snacks, and soft drinks $(p<0.05)$. In contrast, there was no difference between men and women in their listing of ice cream, pasta dishes, potatoes and french fries.

As shown in Table 2, nine out of 25 carbohydrate sources were also major sources of fat. Approximately a third of the men (32.6\%) and $39.8 \%$ of the women listed carbohydrate/fat sources (doughnuts, white bread, ice cream, pasta dishes, french fries and salty snacks) among their favorite foods. At least three of the carbohydrate/fat sources (doughnuts, pies, and ice cream) can be regarded as sweet. In contrast, only $5.4 \%$ of the men and $4.9 \%$ of the women listed carbohydrate sources (sugar, fruit juices, cereals and rice) that did not contain fat. The present findings suggest, first, that preferences for carbohydrate/fat sources are far more common than preferences for carbohydrate sources $(p<0.01)$, and second, that preferences for carbohydrate/fat mixtures are more common among women than among men.

\section{Fat sources}

Major nutrient sources of fat in the U.S. diet are summarized in Table 3. According to Block et al. (1985), the category of hamburgers, cheeseburgers and meatloaf contributes the largest percentage of fat calories to the diet $(7.0 \%)$; 
TABLE 2

Obese respondents' preferences for foods that are major sources of carbohydrate in the U.S. diet. Food list based on National Health and Nutrition Examination Survey (NHANES II), U.S. 1976-80, as cited by Block et al. (1985)

\begin{tabular}{|c|c|c|c|c|}
\hline \multirow[b]{2}{*}{ Rank } & \multirow[b]{2}{*}{ Description } & \multicolumn{2}{|c|}{ Percentage of } & \multirow[b]{2}{*}{$\begin{array}{c}\text { Source } \\
\text { of fat }\end{array}$} \\
\hline & & $\begin{array}{c}\text { Women } \\
(n=386)\end{array}$ & $\begin{array}{c}\text { Men } \\
(n=93)\end{array}$ & \\
\hline 1. & White bread, rolls, crackers & $54 \cdot 4^{* *}$ & $37 \cdot 6$ & $x$ \\
\hline 2. & Regular soft drinks & $7 \cdot 3^{*}$ & $1 \cdot 1$ & \\
\hline 3. & Doughnuts, cookies, cake & $56 \cdot 2^{* *}$ & $39 \cdot 8$ & $x$ \\
\hline 4. & Sugar & $0 \cdot 3$ & - & \\
\hline 5. & Whole milk, milk beverages & $6 \cdot 0$ & $6 \cdot 5$ & $x$ \\
\hline 6. & French fries, fried potatoes & $14 \cdot 2$ & $18 \cdot 3$ & $x$ \\
\hline 7. & Alcoholic beverages & $4 \cdot 1$ & $4 \cdot 3$ & \\
\hline 8. & Whole wheat, dark breads & 1.6 & $1 \cdot 1$ & \\
\hline 9. & Orange juice & $1 \cdot 0$ & $-m$ & \\
\hline 10. & Potatoes, excl. fried & $29 \cdot 5$ & $26 \cdot 9$ & \\
\hline 11. & Coffee, tea & 1.8 & $2 \cdot 2$ & \\
\hline 12. & Spaghetti and pasta & $39 \cdot 1$ & $37 \cdot 6$ & $x$ \\
\hline 13. & Ice cream, frozen desserts & $51 \cdot 3$ & $49 \cdot 5$ & $x$ \\
\hline 14. & Fruit juices & 1.8 & $2 \cdot 2$ & \\
\hline 15. & Cold cereals & $3 \cdot 6$ & $7 \cdot 5$ & \\
\hline 16. & Pies, excl. pumpkin & $7 \cdot 3$ & $8 \cdot 6$ & $x$ \\
\hline 17. & Pinto, navy, dried beans & $2 \cdot 6$ & - & \\
\hline 18. & $2 \%$ milk & - & - & $x$ \\
\hline 19. & Cornbread, grits, tortillas & 0.8 & 1.1 & \\
\hline 20. & Salty snacks & $23 \cdot 8^{*}$ & $12 \cdot 9$ & $x$ \\
\hline 21 . & Apples, applesauce & 4.4 & $4 \cdot 3$ & \\
\hline 22. & Rice & $14 \cdot 0$ & $11 \cdot 8$ & \\
\hline 23. & Fortified fruit drinks & - & - & \\
\hline 24. & Jellies, jams, honey & 0.3 & $2 \cdot 2$ & \\
\hline 25. & Candy (chocolate) & $32 \cdot 4^{* *}$ & $15 \cdot 1$ & \\
\hline
\end{tabular}

${ }^{*}=p<0.05 ; * *=p<0.01$.

followed by hot dogs, ham and lunch meat $(6.4 \%)$ and whole milk and milk beverages $(6.0 \%)$. Together, the 25 food categories contribute a cumulative total of $81.6 \%$ of fat calories to the population diet.

As shown in Table 3, preferences for major nutrient sources of fat were more widespread than preferences for carbohydrate. Moreover, protein/fat sources (meat products) figured prominently among favorite foods of both women and men. However, beef dishes were named by significantly more men than women. As many as $72 \%$ of the men but only $41.2 \%$ of the women listed steak or roast among their favorite foods. More men than women expressed preferences for hot dogs, bacon and sausage, eggs, and salad and cooking oils. In contrast, more women than men expressed preferences for cheeses. As noted above, more women than men expressed preferences for carbohydrate/fat mixtures.

\section{Protein sources}

The chief nutrient sources of protein are listed in Table 4. According to Block et al. (1985), beef steaks and roasts account for $12.6 \%$ of dietary protein; hamburgers, cheeseburgers and meatloaf for $8.9 \%$, and white bread, rolls and crackers 


\section{TABLE 3}

Obese respondents' preferences for foods that are major sources of fat in the U.S. diet. Food list based on National Health and Nutrition Examination Survey (NHANES II), U.S. 1976-80, as cited by Block et al. (1985)

\begin{tabular}{|c|c|c|c|c|}
\hline \multirow[b]{2}{*}{ Rank } & \multirow[b]{2}{*}{ Description } & \multicolumn{2}{|c|}{ Percentage of } & \multirow[b]{2}{*}{$\begin{array}{l}\text { Source } \\
\text { of } \mathrm{CHO}\end{array}$} \\
\hline & & $\begin{array}{l}\text { Women } \\
(n=386)\end{array}$ & $\begin{array}{c}\text { Men } \\
(n=93)\end{array}$ & \\
\hline 1. & Hamburgers, cheeseburgers, meatloaf & $18 \cdot 4$ & $25 \cdot 8$ & \\
\hline 2. & Hot dogs, ham, lunch meats & $9 \cdot 3$ & $25 \cdot 8^{* *}$ & \\
\hline 3 . & Whole milk, milk beverages & $6 \cdot 0$ & 6.5 & $x$ \\
\hline 4. & Doughnuts, cookies, cake & $56 \cdot 2^{* *}$ & 39.8 & $x$ \\
\hline 5. & Beef steaks, roasts & $41 \cdot 2$ & $72 \cdot 0^{* *}$ & \\
\hline 6. & White brcad, rolls, crackers & $54 \cdot 4^{* *}$ & $37 \cdot 6$ & $x$ \\
\hline 7. & Eggs & $11 \cdot 7$ & $23 \cdot 7^{* *}$ & \\
\hline 8. & Cheeses, excl. cottage cheese & $37 \cdot 6^{*}$ & $26 \cdot 9$ & \\
\hline 9. & Margarine & - & - & \\
\hline 10. & Mayonnaise, salad dressings & $6 \cdot 5$ & $2 \cdot 2$ & \\
\hline 11. & Pork, incl. chops, roast & $9 \cdot 1$ & $10 \cdot 8$ & \\
\hline 12. & French fries, fried potatoes & $14 \cdot 2$ & $18 \cdot 3$ & $x$ \\
\hline 13. & Salad and cooking oils & $0 \cdot 3$ & $5 \cdot 4^{* *}$ & \\
\hline 14. & Butter & $10 \cdot 1$ & $5 \cdot 4$ & \\
\hline 15. & Ice cream, frozen desserts & $51 \cdot 3$ & $49 \cdot 5$ & $x$ \\
\hline 16. & Salty snacks & $23 \cdot 8^{*}$ & $12 \cdot 9$ & $x$ \\
\hline 17. & Peanuts, peanut butter & $5 \cdot 2$ & $6 \cdot 5$ & \\
\hline 18. & Pies. excl. pumpkin & $7 \cdot 3$ & $8 \cdot 6$ & $x$ \\
\hline 19. & Bacon & $2 \cdot 8$ & $7 \cdot 5^{*}$ & \\
\hline 20. & $2 \%$ milk & - & - & $x$ \\
\hline 21. & Spaghetti and pasta & $39 \cdot 1$ & $37 \cdot 6$ & $x$ \\
\hline 22. & Sausage & $2 \cdot 1$ & $10 \cdot 8^{* *}$ & \\
\hline 23. & Chicken or turkey, excl. fried & $37 \cdot 0$ & $40 \cdot 9$ & \\
\hline 24. & Fried fish & $2 \cdot 1$ & $2 \cdot 2$ & \\
\hline 25. & Gravy, other meat sauces & $6 \cdot 2^{*}$ & $1 \cdot 1$ & \\
\hline
\end{tabular}

$*=p \leqslant 0.05 ; * *=p<0.01$.

for $6.9 \%$. Since much of the dietary protein derives from meat and dairy products, the chief nutrient sources of protein are also major sources of dietary fat. The listed foods contribute a cumulative total of $81.2 \%$ of protein to the diet.

Protein sources, especially protein/fat sources were frequently listed among the favorite foods of obese women and men. However, while more men than women named steaks, hot dogs, eggs and fish $(p<0.05)$, more women than men named doughnuts, white bread and cheese $(p<0.05)$. Substantial proportions of men and women also named protein sources that were not major sources of fat, notably potatoes (excluding fried), pizza and fish. The present data provide no support for the notion that most obese men and women fail to show preferences for high-protein foods.

\section{Item frequency scores}

Frequency scores were based on the average number of times that instances of a given food category appeared on a single list of 10 favorite foods. These data are shown in Table 5. On average, women listed a significantly higher number of 


\section{TABLE 4}

Obese respondents' preferences for foods that are major sources of protein in the U.S. diet. Food list based on National Health and Nutrition Examination Survey (NHANES II), U.S. 1976-80, as cited by Block et al. (1985)

\begin{tabular}{|c|c|c|c|c|}
\hline \multirow[b]{2}{*}{ Rank } & \multirow[b]{2}{*}{ Description } & \multicolumn{2}{|c|}{ Percentage of } & \multirow[b]{2}{*}{$\begin{array}{c}\text { Source } \\
\text { of fat }\end{array}$} \\
\hline & & $\begin{array}{l}\text { Women } \\
(n=386)\end{array}$ & $\begin{array}{c}\text { Men } \\
(n=93)\end{array}$ & \\
\hline 1. & Beef steaks, roasts & $41 \cdot 2$ & $72 \cdot 0^{* *}$ & $x$ \\
\hline 2. & Hamburgers, cheeseburgers, meatloaf & $18 \cdot 4$ & $25 \cdot 8$ & $x$ \\
\hline 3. & White bread, rolls, crackers & $54 \cdot 4 * *$ & $37 \cdot 6$ & $x$ \\
\hline 4. & Whole milk, milk beverages & $6 \cdot 0$ & 6.5 & $x$ \\
\hline 5. & Pork, incl. chops, roast & $9 \cdot 1$ & 10.8 & $x$ \\
\hline 6. & Hot dogs, ham, lunch meats & $9 \cdot 3$ & $25 \cdot 8^{* *}$ & $x$ \\
\hline 7. & Eggs & $11 \cdot 7$ & $23 \cdot 7^{* *}$ & $x$ \\
\hline 8. & Chicken or turkey, excl. fried & $37 \cdot 0$ & $40 \cdot 9$ & $x$ \\
\hline 9. & Cheeses, excl. cottage cheese & $37 \cdot 6^{*}$ & $26 \cdot 9$ & $x$ \\
\hline 10. & $2 \%$ milk & - & - & $x$ \\
\hline 11. & Fried chicken & $6 \cdot 7$ & $4 \cdot 3$ & \\
\hline 12. & Spaghetti and pasta & $39 \cdot 1$ & $37 \cdot 6$ & $x$ \\
\hline 13. & Doughnuts, cookies, cake & $56 \cdot 2^{* *}$ & 39.8 & $x$ \\
\hline 14. & Skim milk, buttermilk & $0 \cdot 3$ & - & \\
\hline 15. & Fried fish & $2 \cdot 1$ & $2 \cdot 2$ & $x$ \\
\hline 16. & Whole wheat, rye bread & 1.6 & $1 \cdot 1$ & \\
\hline 17. & Pinto, navy, dried beans & $2 \cdot 6$ & - & \\
\hline 18. & Fish, broiled, baked, canned & 14.8 & $32 \cdot 3^{* *}$ & \\
\hline 19. & Tuna, tuna salad, casserole & $5 \cdot 4$ & $7 \cdot 5$ & \\
\hline 20. & Chili & 1.8 & $2 \cdot 2$ & \\
\hline 21. & Pizza & $30 \cdot 1$ & $31 \cdot 2$ & \\
\hline 22. & Peanuts, peanut butter & $5 \cdot 2$ & $6 \cdot 5$ & $x$ \\
\hline 23. & French fried, fried potatoes & $14 \cdot 2$ & $18 \cdot 3$ & $x$ \\
\hline 24. & Potatoes, excl. fried & $29 \cdot 5$ & 26.9 & \\
\hline 25. & Beef stew, pot pie & - & - & \\
\hline
\end{tabular}

$*=p \leqslant 0.05 ;{ }^{* *}=p<0.01$.

carbohydrate sources (4.1 per list of ten) than did men (3.2); $p<0 \cdot 001)$. However, the observed preferences for carbohydrates were largely accounted for by preferences for carbohydrate/fat sources. Carbohydrate/fat sources were listed far more often by both men and women than carbohydrate sources that were not major sources of fat; $p<0.001$. Women listed more carbohydrate/fat sources $(3.0$ per list) than did men $(2.4) ; p<0.001$. Women also listed more carbohydrate sources than were not sources of fat $(1 \cdot 10)$ than did men $(0.79) ; p<0.001$.

On average, both men and women listed more fat sources than carbohydrate sources among their favorite foods. Women listed an average of 5.2 fat sources as opposed to $4 \cdot 1$ carbohydrate sources; the difference between the two was significant, $p<0.001$. Men listed an average of 5.4 fat sources as opposed to 3.2 carbohydrate sources; this difference was also significant; $p<0.001$.

On average, men listed somewhat more protein sources $(5.4$ per list) than did women (4.9); $p<0.05$. However, most of these were protein/fat sources (men: 4.3; women: 4.0 ) rather than protein sources that were not major sources of fat (women: $2 \cdot 5$; men: 1.9 ). 
TABLE 5

A summary of item frequency scores. Item frequency score is the average number of times that foods belonging to a given category occurred on a single list of ten favorite foods

\begin{tabular}{lcllll}
\hline & $\begin{array}{c}\text { Number of } \\
\text { sources }\end{array}$ & \multicolumn{2}{c}{ Women $(n=386)$} & \multicolumn{2}{c}{ Men $(n=93)$} \\
& Mean & SD & Mean & SD \\
\hline Carbohydrate sources & 25 & $4 \cdot 1^{* *}$ & 1.8 & 3.2 & 1.7 \\
Fat sources & 25 & $5 \cdot 2$ & 1.8 & 5.4 & 1.9 \\
Protein sources & 25 & 4.9 & 1.7 & $5.4^{*}$ & 1.9 \\
Carbohydrate/fat sources & 9 & $3.0^{* *}$ & 1.6 & 2.4 & 1.4 \\
Protein/fat sources & 15 & 4.0 & 1.6 & 4.3 & 1.8 \\
Protein/carbohydrate sources & 9 & 2.5 & 1.4 & 1.9 & 1.1 \\
Carbohydrate (non-fat) & 16 & $1.1^{* *}$ & 0.9 & 0.8 & 0.7 \\
Fat (non-carbohydrate) & 16 & 2.1 & 1.3 & $3.0 * *$ & 1.7 \\
Protein (non-fat) & 10 & 0.9 & 0.8 & 1.1 & 0.9 \\
\hline
\end{tabular}

${ }^{*}=p<0.05 ;{ }^{* *}=p<0.01$.

\section{Preferences for food groups}

Preferences for foods belonging to the 11 mutally exclusive food groups are shown in Table 6. This analysis was based on the complete set of favorite foods listed by obese men and women. The data include both the percentage of respondents who listed an instance of one of the food groups at least once, as well as the average number of times that items belonging to each food group occurred on the same list (frequency score).

\section{TABLE 6}

Food preferences of obese men and women. The data are the subject percentage score (\% subjects listing) and item frequency score (mean number of times per list)

\begin{tabular}{|c|c|c|c|c|c|}
\hline & & \multicolumn{2}{|c|}{ Men $(n=93)$} & \multicolumn{2}{|c|}{ Women $(n=386)$} \\
\hline & & $\begin{array}{l}\text { \% subjects } \\
\text { listing }\end{array}$ & $\begin{array}{l}\text { \# times } \\
\text { per list }\end{array}$ & $\begin{array}{l}\% \text { subjects } \\
\text { listing }\end{array}$ & $\begin{array}{l}\text { \# times } \\
\text { per list }\end{array}$ \\
\hline 1. & Meats & $96 \cdot 8^{* *}$ & $3 \cdot 6^{* *}$ & $86 \cdot 0$ & $2 \cdot 4$ \\
\hline 2. & Dairy products & $50 \cdot 5$ & $1 \cdot 3$ & $49 \cdot 2$ & $1 \cdot 3$ \\
\hline 3. & Fats & $16 \cdot 1$ & $1 \cdot 1$ & $23 \cdot 8$ & $1 \cdot 3$ \\
\hline 4. & Vegetables & $39 \cdot 8$ & 1.4 & $48 \cdot 4$ & $1 \cdot 4$ \\
\hline 5. & Fruit & $29 \cdot 0$ & $1 \cdot 3$ & 38.9 & $1 \cdot 3$ \\
\hline 6. & Starches & $44 \cdot 1$ & $1 \cdot 3$ & $49 \cdot 2$ & $1 \cdot 3$ \\
\hline 7. & Sugars & $11 \cdot 8$ & $1 \cdot 0$ & $23 \cdot 3$ & $1 \cdot 1$ \\
\hline 8. & High-fat sweets & $67 \cdot 7$ & $2 \cdot 0$ & $80 \cdot 6^{* *}$ & $2 \cdot 3^{*}$ \\
\hline 9. & Carbohydrate/fat & $92 \cdot 5$ & $2 \cdot 6$ & $91 \cdot 5$ & $2 \cdot 6$ \\
\hline 10. & Low cal beverages & $3 \cdot 2$ & $1 \cdot 3$ & $3 \cdot 4$ & $1 \cdot 1$ \\
\hline 11. & Alcohol & $4 \cdot 3$ & 1.0 & $4 \cdot 1$ & $1 \cdot 1$ \\
\hline
\end{tabular}

" $=p<0.05 ; * *=p<0.01$. 
Men were most likely to list meat dishes among their favorite foods. As shown in Table 5, 96.8\% of obese men named at least one instance of a meat dish per list. On average, men named 3.6 different meat dishes per list. In contrast, only $86.0 \%$ of women named meats among their favorite foods, naming meat dishes on average 2.4 times per list. Both these differences were statistically significant.

Significant differences in the opposite direction were obtained for sweet carbohydrate/fat sources. As many as $80.6 \%$ of the women but only $67.7 \%$ of the men named at least one instance of sweet high-fat foods among their favorites $(p<0.05)$. On average, women named 2.3 instances of such foods per list, while men named $2.0(p=0 \cdot 10)$. Women were also more likely than men to name sweet but lowfat carbohydrates among their favorite foods $(23.3$ vs. $11.8 \%)$. In contrast to widespread preferences for meats, dairy products and sweet desserts, obese subjects expressed preferences for vegetables, fruit and other starchy foods infrequently.

\section{Discussion}

The present data, based on a systematic study of food preferences of a large sample of obese men and women provide no support for the hypothesis (Wurtman et al., 1985) that selective preferences for carbohydrates as opposed to other foods are a characteristic feature of human obesity. On the contrary, the most frequently expressed preferences were for those food categories that are major nutrient sources of fat in the American diet (Block et al., 1985). Carbohydrates were listed less frequently, and only if they were also major sources of fat, or were sweet.

Men and women differed substantially in their food preference profiles. While obese men listed predominantly fat and fat/protein sources (meat dishes) among their favorite foods, obese women listed more carbohydrate/fat sources and more foods that were sweet (doughnuts, cookies, cake). Although the subjects were not asked to list the foods in any particular order, the food listed first by most men was steak, and by most women, ice cream.

Recent literature on food preferences in obesity has been dominated by reports of "carbohydrate cravings", said to be observed among a vast majority of obese people (Wurtman et al., 1981, 1985; Lieberman et al., 1986) and caused by serotonin imbalance. According to one report, a history of carbohydrate cravings was elicited from most obese persons presenting themselves for treatment at a weight-loss clinic (Heraief et al., 1985). In another study, extensive advertising for obese subjects yielded a group of 186 carbohydrate cravers but only 19 non-carbohydrate cravers, the latter defined as people who predominantly selected protein-based snacks (Lieberman et al., 1986). The usual implication has been that carbohydrate cravings are a population-wide phenomenon that is equally characteristic of both obese women and men.

The "carbohydrate cravings" hypothesis lends itself to several testable predictions. First, if most obese individuals are indeed carbohydrate cravers (Lieberman et al., 1986), then preferences for dietary sources of carbohydrate should be a common characteristic of most human obesity syndromes. Second, given that carbohydrate cravings are viewed as a behavioral consequence of serotonin imbalance (Wurtman et al., 1985), the same pattern of carbohydrate preference should be obtained equally for both women and men. By the same token, if carbohydrate 
cravings are centrally mediated and macronutrient-specific, preferences for carbohydrates should be independent of the sweet taste of foods. Third, no appreciable preferences for protein-type foods should be observed among obese individuals. Since other amino acids compete with tryptophan for uptake into the brain, overconsumption of protein/fat mixtures should aggravate serotonin imbalance in susceptible obese persons, reducing satiety and causing depression and fatigue. Finally, since carbohydrates with a high glycemic index most effectively promote tryptophan uptake by the brain and so redress serotonin imbalance, foods such as potato starch ought to be the most common object of food cravings (Wurtman et al., 1989).

None of these predictions have been confirmed by the present results. First, preferences for nutrient sources of fat outweighed those for sources of carbohydrate. Second, obese men and women showed very distinct profiles of food preference. The sweet taste of foods was a major factor in determining food preferences, particularly among women. Third, both men and women listed several high-protein meat dishes among their favorite foods. Steak and ice cream rather than starches typically headed the list of preferred foods.

Preferences for carbohydrate-rich foods in the obese population may not be as widespread as previously supposed. Part of the problem may lie in the misclassification of carbohydrate-rich foods (Drewnowski, 1988). Fat and not carbohydrate often provides the bulk of calories in chocolates, cakes, pastry and ice cream. Such snacks should be classified as sugar/fat mixtures rather than as carbohydrate-rich foods. Although food cravings undoubtedly exist, the nutrient-specific term "carbohydrate craving" may be a misnomer, denoting sensory preferences for foods that are sweet, rich in fat, or both (Drewnowski, 1988).

While the observed preferences of obese women were overwhelmingly in the direction of carbohydrate/fat sources, a small proportion of women did report preferences for carbohydrates that were neither sweet nor contained fat. Accordingly, it is possible that the carbohydrate craving phenomenon does exist, but is limited to a relatively small segment of the obese population, and is moreover largely restricted to obese women. Although nothing in the serotonin hypothesis would suggest it, "carbohydrate craving" appears to be a gender-dependent phenomenon.

Thus another reason for overstating the contribution of carbohydrate cravings to human obesity may be that most clinic patients are women. The typical obese patient in a weight reduction program is a woman in her 40 s who has previously tried and failed to lose weight. In most clinical populations studied, women patients outnumbered men four to one (Blackburn et al., 1989; Price et al., 1990). Given the high proportion of women in most study samples, it may appear that the entire obese population craves sweet carbohydrates that are rich in fat. The present data showed that preferences for carbohydrates and carbohydrate/fat sources were in fact much more common among women than among men. While men listed steaks and roasts, hamburgers and other meat dishes, it was women who named doughnuts, white bread, chocolate or ice cream among their most preferred foods.

The role of taste factors also deserves some attention. Food preferences are often influenced by taste responses to specific foods. Elevated sensory preferences for dietary fats may be associated with some forms of human obesity. In one past study (Drewnowski et al., 1985), massively obese women patients gave highest ratings to taste stimuli that were rich in fat. In other studies, sensory preferences for fat in foods were linked with the subjects' percentage of body fat, though admittedly not 
with fat consumption (Mela \& Sacchetti, 1991). While elevated preferences for dietary fats have not been obtained with all samples of obese individuals (Drewnowski et al., 1991; Warwick \& Schiffman, 1990), recent data indicate that elevated preferences for sweet high-fat foods may be associated not so much with obesity per se, but with a pattern of weight loss and weight gain (Drewnowski et al., 1991). Clinical observations further indicate that cravings for such foods as cakes, cookies, ice cream or chocolate are associated with obesity and are a common obstacle to successful weight reduction. Although bread, potatoes, and pasta dishes do figure prominently in some reports of food preferences and food cravings, they are often overshadowed by liking for high-fat meats, especially as reported by overweight males (Meiselman, 1977). Given that men commonly prefer protein/fat mixtures while women prefer carbohydrate/fat mixtures, it may be that elevated preferences for nutrient sources of fat as opposed to other foods are a primary characteristic of human obesity syndromes.

The question remains whether food preferences are indicative of food consumption. This is still a controversial issue. In past studies, scores on food preference checklists were linked to food choices during a subsequent meal (Hill \& Blundell, 1982/83). One existing population-based dietary intake survey is consistent with our observation that men and women prefer different nutrient sources of fat. While NHANES II data indicate that red meat is the major source of fat calories in the U.S. diet, USDA surveys indicate that the chief nutrient sources of fat for women aged between 25-50 are margarine, milk, shortening and salad dressing (Hepburn, personal communication).

The present findings have important implications for dietary intervention in the treatment of obesity. Current research indicates that excess consumption of dietary fat rather than carbohydrate plays a major role in the development of the obese state (Dreon et al., 1988; Romieu et al., 1988). Most weight-loss diets now emphasize increased carbohydrate consumption and decreased intakes of protein and fat. As a result, limiting carbohydrate preferences in obesity would not appear to be a viable treatment strategy. Pharmaceutical and dietary therapies had best focus on treatments that promote carbohydrate intakes while suppressing preferences for protein and fat. Promoting rather than suppressing carbohydrate cravings may be a novel strategy for weight reduction.

\section{REFERENCES}

Anonymous (1990) Could I be addicted to sweets? Lose Weight Naturally, 4, 10.

Blackburn, G. L., Wilson, G. T., Kanders, B. S., Stein, L. J., Lavin, P. T., Adler, J. \& Brownell, K. D. (1989) Weight cycling: the experience of human dieters. The American Journal of Clinical Nutrition, 49, 1105-1109.

Block, G., Dresser, C. M., Hartman, A. M. \& Carroll, M. D. (1985) Nutrient sources in the American diet: quantitative data from the NHANES II survey. American Journal of Epidemiology, 122, 27-40.

Blundell, J. E. \& Hill, A. J. (1988) Descriptive and operational study of eating in humans. In B. J. Blinder, B. F. Chaitin \& R. Goldstein (Eds), The Eating Disorders. New York: PMA Publishing Group.

Blundell, J. E. \& Rogers, P. J. (1980) Effects of anorectic drugs on food intake, food selection and preferences and hunger motivation and subjective experiences. Appetite, 1, 151-165.

Chiodo, J. \& Latimer, P. R. (1986) Hunger perceptions and satiety responses among normalweight bulimics and normals to a high-calorie, carbohydrate-rich food. Psychological Medicine, 16, 343-349. 
Dreon, D. M., Frey-Hewitt, B., Ellsworth, N., Williams, P. T., Terry, R. B. \& Wood, P. D. (1988) Dietary fat:carbohydrate ratio and obesity in middle-aged men. American Journal of Clinical Nutrition, 47, 955-1000.

Drewnowski, A. (1983) Fats and food texture: sensory and hedonic evaluations. In H. R. Moskowitz (Ed), Food texture, New York: Marcel Dekker, pp. 629-633.

Drewnowski, A. (1988) Changes in mood after carbohydrate consumption. American Journal of Clinical Nutrition, 46, 703.

Drewnowski, A. (1990) Taste and food preferences in human obesity. In E. D. Capaldi \& T. L. Powley (Eds). Taste, experience and feeding. Washington, D.C.: American Psychological Association.

Drewnowski, A., Brunzell, J., Sande, K., Iverius, P. H. \& Greenwood, M. R. C. (1985) Sweet tooth reconsidered: taste responsiveness in human obesity. Physiology \& Behavior, 35, 617-622.

Drewnowski, A., Kurth, C. L. \& Rahaim, J. E. (1991) Taste preferences in human obesity: environmental and familial factors. American Journal of Clinical Nutrition, 54, 635-641.

Drewnowski, A. \& Schwartz, M. (1990) Invisible fats: sensory assessment of sugar/fat mixtures. Appetite, 14, 203-217.

Gates, J. C., Huenemann, R. L. \& Brand, R. J. (1975) Food choices of obese and non-obese persons. Journal of the American Dietetic Association, 76, 339-343.

Heraief, E., Burckhardt, P., Wurtman, J. J. \& Wurtman, R. J. (1985) Tryptophan administration may enhance weight loss by some moderately obese patients on a protein-sparing modified fast (PMSF) diet. International Journal of Eating Disorders, 4, 281-292.

Herman, C. P. (1978) Restrained eating. Psychiatric Clinics of North America, 1, 595-607.

Hill, A. J. \& Blundell, J. E. (1982/83) Nutrients and behavior: research strategies for the investigation of taste characteristics, food preferences, hunger sensations and eating patterns in man. Journal of Psychiatric Research, 17, 203-212.

Lieberman, H. R., Wurtman, J. J. \& Chew, B. (1986) Changes in mood after carbohydrate consumption among obese individuals. American Journal of Clinical Nutrition, 44, 772-778.

Logue, A. W. \& Smith, M. E. (1986) Predictors of food preferences in adult humans. Appetite, $7,109-125$.

Meisselman, H. L. (1977) The role of sweetness in the food preferences of young adults. In J. M. Weiffenbach (Ed) Taste and development: The genesis of sweet preference. DHEW Publ. No. (NIH) 77-1068, US DHEW, NIH, Md.

Meiselman, H. L. \& Waterman, D. (1978) Food preferences of enlisted personnel in the armed forces. Journal of the American Dietetic Association, 73, 621-629.

Mela, D. J. \& Sacchetti, D. A. (1991). Sensory preferences for fats: relationships with diet and body composition. American Journal of Clinical Nutrition, 53, 9089.15.

Najjar, M. F. \& Rowland, M. (1987). Anthropometric reference data and the prevalence of overweight, United States 1976-80. National Center for Health Statistics, Vital Health Statistics, Series 11, 238, 1-73.

Pangborn, R. M., Bos, K. E. \& Stern, J. (1985) Dietary fat intake and taste response to fat in milk by under-, normal-, and overweight women. Appetite, 6, 25-40.

Paykel, E. S., Mueller, P. S. \& de la Vergne, P. M. (1973) Amitryptyline, weight gain and carbohydrate craving: a side effect. British Journal of Psychiatry, 123, 501-507.

Price, R. A., Stunkard, A. J., Ness, R., Wadden, T., Heshka, S., Kanders, B. \& Cormillot, A. (1990). Childhood onset (age < 10) obesity has high familial risk. International Journal of Obesity, 14, 185-195.

Romieu, I., Willett, W. C., Sampfer, M. J., Colditz, G. A., Sampson, L., Rosner, B., Hennekens, C. H. \& Speizer, F. E. (1988). Energy intake and other determinants of relative weight. American Journal of Clinical Nutrition, 47, 406-412.

Smiciklas-Wright, H., Krebs-Smith, S. M. \& Krebs-Smith, J. (1986) Variety in foods. In: Food and Nutrition Board Symposium, What is America Eating? Washington, D.C.: National Academy Press, pp. 126-140.

Tomelleri, R. \& Grunewaid, K. K. (1987) Menstrual cycle and food cravings in young college women. Journal of the American Dietetic Association, 87, 311-315.

Warwick, Z. S. \& Schiffman, S. S. (1990) Sensory evaluations of fat-sucrose and fat-salt mixtures: relationship to age and weight status. Physiology \& Behavior, 48, 633-636. 
Wurtman, J. J. (1984) The involvement of brain serotonin in excessive carbohydrate snacking by obese carbohydrate cravers. Journal of the American Dietetic Association, 84, $1004-1007$.

Wurtman, R. J., O'Rourke, D. \& Wurtman, J. J. (1989). Nutrient imbalance in depressive disorders: possible brain mechanisms. In L. H. Schneider, S. J. Cooper \& K. A. Halmi (Eds). The Psychobiology of Human Eating Disorders. Annals of the New York Academy of Sciences, 575, 75-85.

Wurtman, J. J \& Wurtman, R. J. (1984) D-fenfluramine selectively decreases carbohydrate but not protein intake in obese subjects. International Journal of Obesity, 8, (Suppl. 1), 79-84.

Wurtman, J. J., Wurtman, R. J., Growdon, J. H., Henry, P., Lipscomb, A. \& Zeisel, S. (1981) Carbohydrate craving in obese people: suppression by treatments affecting serotoninergic transmission. International Journal of Eating Disorders, 1, 2-11.

Wurtman, J. J., Wurtman, R., Mark, S., Tsay, R., Gilbert, W. \& Growdon, J. (1985) dFenfluramine selectively suppresses carbohydrate snacking by obese subjects. International Journal of Eating Disorders, 4, 89-99.

Received 29 July 1991, revision 2 December 1991 